This is a postprint of an article published by Springer in Scientometrics on 20 July 2012, available at https://link.springer.com/article/10.1007/s11192-0120816-4.

\title{
Scientific production in psychology: a gender analysis
}

\author{
Maite Barrios; Anna Villarroya, Àngel Borrego
}

\author{
M. Barrios \\ Department of Methodology of Behavioral Sciences, University of Barcelona, \\ Melcior de Palau, 140, 08014 \\ Barcelona, Spain e-mail: \\ mbarrios@ub.edu
}

\author{
A. Villarroya \\ Department of Public Economy, Political Economy and Spanish Economy, \\ University of Barcelona, 08014 \\ Barcelona, Spain e-mail: \\ annavillarroya@ub.edu

\begin{abstract}
Á. Borrego
Department of Library and Information Science, University of Barcelona, 08014 Barcelona, Spain e-mail: borrego@ub.edu
\end{abstract}

\begin{abstract}
:
This study aims to identify possible gender inequalities in the scholarly output of researchers in the field of psychology in Spain. A sample of 522 papers and reviews published in 2007 was extracted from the Thomson ISI Web of Science. The presence of women, the collaboration pattern and the impact of these scientific publications were analyzed. The results show that the average number of female researchers per paper was 0.42 (SD 0.33) and that $42.3 \%$ of the papers had a female researcher as the first author. Moreover, the proportion of female authors of a paper was statistically significantly higher when the first author was female. Studies carried out in cooperation with other Spanish or international institutions had fewer female authors than studies conducted at a single center. The impact of the papers, measured by the journal impact factor and the number of citations, was independent of the authors' gender or the proportion of female authors. In summary, the study highlights a gender imbalance in Spanish scientific output in Psychology, and a higher proportion of male researchers in international networks.

Keywords: Psychology, Scientific Production, Gender Collaboration, Impact Factor, Citations.
\end{abstract}




\section{Introduction}

In recent decades, it has been shown that women receive lower salaries, are less repre- sented in the higher academic ranks and have access to fewer research resources (European Commission 2009). The relevance of scientific publications in the academic world, especially in the fields of promotion, recognition of research periods or access to funding, has made it particularly valuable to study the publication patterns of academic and research scientists.

A substantial part of gender studies has focused on the quantitative analysis of scientific production. Different results have been obtained depending on the countries, disciplines and variables. Although many studies have shown higher productivity among men (Long 1992; Kyvik and Teigen 1996; Prpic 2002; Sax et al. 2002; Stack 2004; Sonnert and Holton 2006; Symonds et al. 2006; Ledin et al. 2007; Hunter and Leahey 2010; Puuska 2010; Larivière et al. 2011), others have found no significant differences in productivity among men and women (Ward and Grant 1995; Dasaratha et al. 1997; Xie and Shauman 1998; Lewison 2001; Bordons et al. 2003; Gallivan and Benbunan-Fich 2006; Tower et al. 2007; Mauleón et al. 2008).

In addition to the quantitative analysis of scientific production, a relevant indicator of academic success is the impact of publications. This is examined through an analysis of citations and the journal impact factor. The literature has shown mixed results in this area, including no differences in the citation patterns of male and female academics (Cole and Zuckerman 1984; Lewison 2001; Ledin et al. 2007; Mauleón et al. 2008; Copenheaver et al. 2010), a higher number of citations of female-authored papers (Long 1992; Symonds et al. 2006; Borrego et al. 2010) and fewer citations of papers by women (Hunter and Leahey 2010; Larivière et al. 2011). Studies on the journal impact factor have also had mixed findings. They have highlighted the similarity of the journals in which men and women publish (Lewison 2001; Bordons et al. 2003; Mauleón and Bordons 2006; Gon- zálezBrambila and Veloso 2007; Mauleón et al. 2008), shown that men choose to publish in journals with a higher impact factor (Hunter and Leahey 2010) or indicated that women tend to publish in higher impact journals (Borrego et al. 2010).

A different approach to the study of scientific activity is based on the collaborative practices of researchers, analyzed by the average number of authors per paper and the frequency of papers produced in national and international collaborations. With the exception of some studies (Cole and Zuckerman 1984; Long 1992), the literature has shown that women do not tend to work in collaboration with foreign authors (Lemoine 1995; Lewison 2001; Webster 2001; Larivière et al. 2011) because they have a smaller network of contacts (Renzulli et al. 2000), are less willing to travel abroad (Lewison 2001) or are even reluctant to collaborate with scientists from their own university departments (Webster 2001). Empirical studies of authorship patterns have had mixed results. Some research shows similar rates of co-authorship among men and women (McDowell et al. 2005), whilst other studies found that women have significantly lower rates of co- authorship than men (Boschini and Sjogren 2007).

These differences can be explained by aspects of the study, such as the country in which it is carried out, the time period analyzed, the methodology applied, the type of institution evaluated and, above all, the scientific field that is evaluated. To address the fact that women are not represented to the same extent as men in all areas of science, the present study examines potential gender inequalities in scientific psychology literature, an area in which traditionally, a high proportion of psychology graduate students and academics are women. Although psychology is an area of intense interest among academics (Duffy et al. 
2011), the results are far from conclusive. The first studies on gender inequality in psychology were carried out in the US and found either a weak relationship between gender and the number of papers published (Guyer and Fidell 1973) or similar productivity patterns among men and women (Boice et al. 1985; Black and Holden 1998). However, more recent studies on academics in Italy (D'Amico et al. 2011), Australia (Malouff et al. 2010), Spain (González-Alcaide et al. 2010) and Americ (Joy 2006) show lower pro- ductivity of women, especially in international journals (D'Amico et al. 2011). Results on the impact of publications have also been mixed, including findings of no differences between genders (Haslam et al. 2008) and a greater impact of papers by men (Nosek et al. 2010). In Spain, a study by Mestre-Escriva' et al. (1996) on the papers published in a specific journal during 1977-1995 showed a clear imbalance in the presence of women as first authors. More recently, Olivas-Avila and Musi-Lechuga (2010) have found a low proportion of women among the most productive authors in the field of psychology. In particular, of the ten most productive psychology authors in the country, only one was a woman. Olivas-Avila and Musi-Lechuga (2010) also note that not all academic areas in psychology are equally productive, although a low percentage of women with high sci- entific production appear in all of them.

In this context, we focused on analyzing the scientific production of Spanish authors in the field of psychology over a specific period of time. The aim was to address the three key areas in which gender inequalities have been detected in other disciplines and countries: the authorship of scientific papers, the patterns of collaboration of researchers, and the impact of the publications, assessed by the number of citations and the journal impact factor.

\section{Methods}

There is one major obstacle to the method in gender studies: most databases, including the Thomson Reuters ISI Web of Science (WoS) that is usually the main source of bibliometric data in this kind of studies, identify authors by their surname and the first initial of their first name. This makes it difficult to determine their gender. However, in 2007 the WoS began to incorporate authors' full names, which facilitates the identification of their gender.

From the WoS database, we selected all the documents classified as papers or reviews that were published in 2007 in one of the 11 categories of psychology and in which Spain was mentioned in the affiliation of the corresponding author. In total, 652 documents were retrieved. The final sample was composed of 522 documents, as we eliminated documents in which the author's gender could not be identified or the full name was not included.

The rules for the order of co-authors vary significantly between disciplines. In psychology, authors are predominantly specified according to their intellectual contribution (Einav and Yariv 2006). Therefore, for each document, we identified the gender of the first author and the corresponding author. We also calculated the proportion of female authors of the paper, as well as the proportion of female authors taking into account the gender of the first author. Moreover, the number of papers written by a single author was calculated, although this last item was not considered in the analysis of collaboration.

The types of institutional collaboration were evaluated on the basis of the author's institution, so documents were classified as: "national", "international" or "no collaboration'. Papers produced with the participation of different departments or sections in the same institution or with different institutions in the Spanish territory were classified as "national collaboration"; those drawn up in collaboration with other countries as 
"international collaboration"; and those written by authors in the same institution and department as "no collaboration".

The impact of papers was measured by the journal impact factor and the number of citations received by every paper from its publication until 2011. The journal impact factor was obtained from the science and social science versions of the Journal Citation Reports database.

The statistical analysis was performed using the statistical program SPSS 17. For all comparisons, the level of statistical significance was set at $p<0.05$.

\section{Results}

The areas with the highest number of publications were multidisciplinary psychology $(n=220,26.96 \%)$, experimental psychology $(n=129,15.81 \%)$ and clinical psychology $(n=124,15.20 \%)($ see Table 1$)$.

\section{Presence of women per paper}

Of the total number of papers, $42.3 \%[n=221$, confidence interval (CI) 46.53-38.06 \%] had female first authors and the remaining $57.7 \%(n=301$, CI 61.9-53.4 \%) had male. Although the presence of female authors should be around $50 \%$ [according to the Spanish National Statistics Institute (INE 2011), the percentage of female academics in the field of psychology in Spanish public universities was 52.5 and $53 \%$ in the academic years 20062007 and 2007-2008 respectively], the data show a significantly lower proportion of women who published as first author $(p=0.001$ ). Regarding the gender of the corresponding author, data show the same pattern: in $39.7 \%$ of cases $(n=207$; IC $43.8-35.5 \%)$ was a woman and $60.3 \%(n=315$; IC $64.5-56.1 \%)$, was a man. This imbalance was also statistically significant $(p<0.001)$.

The average proportion of women per paper was 0.42 [standard deviation (SD) 0.33 , CI $0.462-0.378$ ). This indicates that the presence of women was lower than expected, according to the INE data (INE 2011).

There was a statistically significant difference in the proportion of papers with only male or female authors $(p<0.001)$. Specifically, while $27.4 \%(n=143$, CI $31.22-$ $23.57 \%)$ of the papers were exclusively by male authors, just $12.1 \%(n=63$, CI 14.89 $9.30 \%$ ) were by women only.

The data also show a statistically significant difference in the proportion of female authors depending on the gender of the first author $(t=2.707, d f=473, p=0.007)$. Thus, when the first author was female, the average proportion of female co-authors per paper was 0.49 (SD 0.38, CI 0.53-0.45), whereas when a man was the first author, the average proportion of women dropped to 0.39 (SD 0.39, CI 0.43-0.35). 
Table 1 Productivity in the

\begin{tabular}{lcc}
\hline Area & No. of papers & Percentage \\
\hline Multidisciplinary psychology & 220 & \\
Experimental psychology & 129 & 26.96 \\
Clinical psychology & 124 & 15.81 \\
Psychology & 85 & 15.20 \\
Social psychology & 56 & 10.42 \\
Biological psychology & 52 & 6.86 \\
Developmental psychology & 49 & 6.37 \\
Educational psychology & 44 & 6.00 \\
Applied psychology & 34 & 5.39 \\
Mathematical psychology & 20 & 4.17 \\
Psychoanalysis & 3 & 2.45 \\
\end{tabular}

different areas of psychology

\begin{tabular}{lcc}
\hline Area & No. of papers & Percentage \\
\hline Multidisciplinary psychology & 220 & \\
Experimental psychology & 129 & 26.96 \\
Clinical psychology & 124 & 15.81 \\
Psychology & 85 & 15.20 \\
Social psychology & 56 & 10.42 \\
Biological psychology & 52 & 6.86 \\
Developmental psychology & 49 & 6.37 \\
Educational psychology & 44 & 6.00 \\
Applied psychology & 34 & 5.39 \\
Mathematical psychology & 20 & 4.17 \\
Psychoanalysis & 3 & 2.45 \\
\hline
\end{tabular}

number of items exceeds the number of documents analyzed, as journals can be classified in one or more areas 
Only $9 \%(n=47$, CI $11.46-6.54 \%)$ of the papers were signed by a single author. The data showed that both sexes produced a similar number of single-authored papers $(z=0.897, p$ $=0.369$ ). The data also showed a similar number of co-authors depending on the gender of the first author (male: mean 3.30, SD 1.77, female: mean 3.54, SD 1.71, $t=1.547, d f=$ 520, $p=0.123$ ).

We found statistically significant differences in the relationship between the proportion of women per paper and the type of collaboration (see Table 2). Thus, the proportion of women in papers published with national or international collaboration was significantly lower than the proportion of women in papers produced within the same institution (no collaboration). This trend was more pronounced when we considered papers that were only by men or women $\left(\mathrm{v}^{2}=28.214, d f=2, p<0.001\right)$. Hence, while the proportion of papers that were exclusively by men was higher in those based on international collaboration, papers by women only were more frequent among those produced in a single institution (no collaboration).

\section{Impact factor and citations}

There were no differences in the impact factor of journals depending on the gender of the first author (Male: mean 1.41, SD 1.10, female: mean 1.40, SD 1.14, $t=0.028, d f=520$, $p=0.977)$. A total of $81.2 \%(n=424)$ of the papers received at least one citation. Papers published with international collaboration received more citations $\left(\mathrm{v}^{2}=20.765, d f=2, p\right.$ $<0.001)$ compared to papers published with national collaboration and nocollaboration. Since men had more publications in this type of collaboration, a covariance analysis was carried out that took into account the type of collaboration as a covariate. The analysis highlighted a number of citations that were similar for both genders (see Table 3). Moreover, the data did not show a statistically significant relationship between the pro- portion of female authors and the number of citations received, controlled by the number of authors who signed each paper and the journal impact factor $\left(r_{\mathrm{AB} . \mathrm{CD}}=-0.085, p=0.052\right)$.

Table 2 Proportion of female authors of the papers by type of collaboration

\begin{tabular}{lllllr}
\hline & Mean (SD) & Statistic & $p$ value & Groups & $p$ value \\
\hline No collaboration & $0.50(0.33)$ & $F(2,469)=12.850$ & $<0.001$ & No C-NC & 0.025 \\
National collaboration & $0.40(0.32)$ & & & No C-IC & $<0.001$ \\
International collaboration & $0.32(0.32)$ & & NC-IC & 0.100
\end{tabular}

$S D$ standard deviation, $F$ Snedecor's $F$ test, $N o C$ no collaboration, $N C$ national collaboration, $I C$ international collaboration 
Table 3 Relationship between the number of citations and the sex of the first author.

$S D$ standard deviation, $I Q R$ interquartile range, $F$ Snedecor's $F$ test.

\section{Discussion}

This study focused on the analysis of scientific production in psychology, a field in which women predominate. The data showed that women were the first authors of a lower proportion of papers than expected and signed as a corresponding author less frequently than men. This last point is especially relevant since in many cases the person responsible for correspondence is the visible head of the research team or the team's senior researcher. The same imbalance was observed in the proportion of women authors in general. In this case, the average proportion of women per paper was 0.42 . This result was no better than that found in the study by Mestre Escriva' et al. (1996) for the period 1977-1995, in which around $40 \%$ of first authors were women towards the end of the study period. Many studies on the presence of women in science have mentioned the "leaky pipeline" phenomenon, which refers to the steady attrition of women at each stage of the academic career ladder. For instance, in Spain the percentages of female enrolled and graduate psychology students in the 2009-2010 academic year were 76.4 and $80.7 \%$, respectively, according to INE data (INE 2011). However, as one moves up the academic ladder the presence of women decreases. This decline begins to be evident at $\mathrm{PhD}$ level, where $62.3 \%$ of $\mathrm{PhD}$ theses are submitted by women. It is further consolidated with entry into a stable academic career, as women occupy $53.8 \%$ of posts (INE 2011). Hence, the participation of women in psychology, which is higher than in other disciplines, is not directly related to the number of women in professional positions in this field or to the generation of scientific publications, as indicated by González-Alcaide et al. (2010). Our results show that despite similar numbers of both genders in academia, scientific production remains unequal. This difference in the number of male and female authors of scientific publications could be due to the influence of various factors. These include personal or family factors, as suggested by Ginther and Kahn (2006) and Ledin et al. (2007), and institutional factors, as described by Xie and Shauman (1998), who found that women had a higher teaching load than men.

Our results also indicated that there is a bias in the presence of women depending on the gender of the first author. Thus, the proportion of female authors is higher when the first author is a woman than when the first author is a man. These results could be explained by the greater propensity of researchers to work with same-sex partners (Ferber and Teiman 1980; McDowell and Smith 1992; Bentley 2003). More recently, this pattern of collaboration has been supported by the results of a study on the preparation, supervision and submission of PhD theses in Spain (Villarroya et al. 2008), which showed how the gender of the $\mathrm{PhD}$ student is clearly related to the gender of the supervisor, and both are related to the gender of the members of the assessment boards.

The percentage of single-authored papers $(9 \%)$ is similar among men and women and both genders tend to publish with a similar number of co-authors. These results are 
consistent with previous studies that found a similar co-authorship rate among men and women and low percentages of single authorship (Cole and Zuckerman 1984; McDowell et al. 2005; Copenheaver et al. 2010). However, these studies report a higher percentage of single-authored papers (around 20 and $24 \%$ ) than in our results. This difference could be explained by varying patterns of collaboration across disciplines.

As regards patterns of collaboration, the results show a lower proportion of women per paper in publications produced through national or international collaboration than in papers produced without external collaboration. These results are consistent with those of Lewison (2001) and Webster (2001) on women researchers in Iceland and Poland, respectively, D'Amico et al. (2011) on the field of psychology in Italy, and those of Larivière et al. (2011) about the faculty in the province of Quebec. All of these studies show that women are less involved in international collaboration than men, probably due to their lower participation in international teams and networks.

Regarding the impact of publications, the analysis of both the number of citations and the journal impact factor showed no gender differences depending on the gender of the first author. This result, which indicates that there is equal recognition of scientific production within the discipline, highlights the need to achieve equality in access to scientific careers, funding and promotion. However, this result is different from that found by the same authors in a previous study that included all disciplines (Borrego et al. 2010). The analysis revealed that papers written by women had a stronger impact, both in terms of the number of citations and the journal impact factor. To some extent, these contradictory results could point to an unequal development of the sexes in different disciplines and in their related patterns of publication (Moya-Anegón et al. 2007; Copenheaver et al. 2010; Olivas-Avila and MusiLechuga 2010; Larivière et al. 2011). As for the number of citations, our results are consistent with those of Haslam et al. (2008) in the international area of psychology and with those of authors who have focused their research on other areas of science (Cole and Zuckerman 1984; Lewison 2001; Bordons et al. 2003; Mauleón and Bordons 2006; Ledin et al. 2007; Mauleón et al. 2008; Copenheaver et al. 2010), who did not find any gender differences in citation patterns.

To date, findings have been mixed on the extent to which (if at all) women are less productive than men in academic research in terms of both quantity and quality (Tower et al. 2007). This is presumably due to the different methodologies used to address the issue (Duffy et al. 2011). Previous studies have shown the differential effect of variables such as age, family characteristics, academic rank, motivation, etc. on scientific production according to gender (Stack 2004; Ledin et al. 2007; Hunter and Leahey 2010). However, when studying scientific production in a particular cohort, these variables present quite homogeneous values. Nevertheless, when studying scientific productivity in a specifictime period, the values of these variables are distributed more heterogeneously and their effects appear to be diluted among male and female researchers. Our study shows how over a specific time period in a discipline such as psychology, which has a high proportion of female researchers, there is a lower presence of women in scientific publications, especially in those involving international collaboration. However, the results do not show differences in the number of citations and in the impact factor of the journals in which men and women publish. Thus, since discrepancies have been identified in the participation of women in science, specifically in the field of psychology, it is important to explore the causes and implement measures to redress this imbalance. Finally, it would be interesting to carry out a longitudinal study of these data as well as to conduct similar studies in other countries and areas of knowledge in order to compare the results reported here with those in other settings. 


\section{Acknowledgments:}

The research reported here was supported by the Spanish Ministry of Education and Science (EA2008-0221).

\section{References}

Bentley, J. T. (2003). Gender differences in the careers of academic scientists and engineers: a literature review. Arlington: National Science Foundation.

Black, M. M., \& Holden, E. W. (1998). The impact of gender on productivity and satisfaction among medical school psychologists. Journal of Clinical Psychology in Medical Settings, 5(1), 117-131.

Boice, R., Shaughnessy, P., \& Pecker, G. (1985). Women and publishing in psychology. American Psychologist, 40(5), 577-578

Bordons, M., Morillo, F., Fernández, T., \& Gómez, I. (2003). One step further in the production of bibliometric indicators at the micro level: differences by gender and professional category of scientists. Scientometrics, 57(2), 159-173.

Borrego, A., Barrios, M., Villarroya, A., \& Ollé, C. (2010). Scientific output and impact of postdoctoral scientists: a gender perspective. Scientometrics, 83(1), 93-101.

Boschini, A., \& Sjogren, A. (2007). Is team formation gender neutral? Evidence from coauthorship patterns. Journal of Labor Economics, 25(2), 325-365.

Cole, J., \& Zuckerman, H. (1984). The productivity puzzle: persistence and change in patterns of publication of men and women scientists. Advances in Motivation and Achievement, 2, 217-258.

Copenheaver, C. A., Goldbeck, K., \& Cherubini, P. (2010). Lack of gender bias in citation rates of publications by dendrochronologists: What is unique about this discipline? Tree-Ring Research, 66(2), $127-133$.

D’Amico, R., Vermigli, P., \& Canetto, S. S. (2011). Publication productivity and career advancement by female and male psychology faculty: the case of Italy. Journal of Diversity in Higher Education, 4(3), $175-184$.

Dasaratha, V. R., Raghunandan, K., Logan, L. B., \& Barkman, B. V. (1997). Gender differences in publications by promoted faculty. Issues in Accounting Education, 12(2), 353-365.

Duffy, R. D., Jadidian, A., Webster, G. D., \& Sandell, K. J. (2011). The research productivity of academic psychologists: assessment, trends, and best practice recommendations. Scientometrics, 28(2), 207-227.

Einav, L., \& Yariv, L. (2006). What's in a surname? The effects of surname initials on academic success. Journal of Economic Perspectives, 20(1), 175-188.

European Commission (2009). She Figures 2009. Statistics and indicators on gender equality in science. Luxembourg: Office for Official Publications of the European Communities.

Ferber, M. A., \& Teiman, M. (1980). Are women economists at a disadvantage in publishing journal articles? Eastern Economics Journal, 6(3-4), 189-193.

Gallivan, M. J., \& Benbunan-Fich, R. (2006). Examining the relationship between gender and the research productivity of IS faculty. In: SIGMIS CPR '06 Proceedings of the 2006 ACM SIGMIS CPR con-ference on computer personnel research: forty four years of computer personnel research: achieve- ments, challenges \& the future (pp. 103-113).

Ginther, D. K., \& Kahn, S. (2006). Does Science Promote Women? Evidence from Academia 1973-2001. NBER Working Paper, 12691. National Bureau of Economic Research, Inc. Available at SSRN: http://ssrn.com/abstract=944179.

González-Alcaide, G., Castelló-Cogollos, L., Bolaños-Pizarro, M., Alonso-Arroyo, A., Valderrama-Zurián, J. C., \& Aleixandre-Benavent, R. (2010). Veinte años de investigación de la psicología española en Psicothema (1989-2008). Psicothema, 22(1), 41-50.

González-Brambila, C., \& Veloso, F. M. (2007). The determinants of research output and impact: a study of Mexican researchers. Research Policy, 36(7), 1035-1051.

Guyer, L., \& Fidell, L. (1973). Publication of men and women psychologists. American Psychologist, 28(2), $157-160$.

Haslam, N., Ban, L., Kaufmann, L., Loughnan, S., Peters, K., Whelan, J., et al. (2008). What makes an article influential? Predicting impact in social and personality psychology. Scientometrics, 76(1), 169-185.

Hunter, L. A., \& Leahey, E. (2010). Parenting and research productivity: new evidence and methods. Social Studies of Science, 40(3), 433-451.

Joy, S. (2006). What should I be doing, and where are they doing it? Scholarly productivity of academic psychologists. Perspectives on Psychological Science, 1(4), 346-364. 
Kyvik, S., \& Teigen, M. (1996). Child care, research collaboration, and gender differences in scientific productivity. Science, Technology, \& Human Values, 21(1), 54-71.

Larivière, V., Vignola-Gagné, E., Villeneuve, E., Gélinas, P., \& Gingras, Y. (2011). Sex differences in research funding, productivity and impact: an analysis of Québec university professors. Scientometrics, $87(3), 483-498$.

Ledin, A., Bornmann, L., Gannon, F., \& Wallon, G. (2007). A persistent problem. EMBO Reports, 8(11), 982-987.

Lemoine, W. (1995). Productivity patterns of men and women scientists in Venezuela. Scientometrics, 24(2), 281-295.

Lewison, G. (2001). The quantity and quality of female researchers: a bibliometric study of Iceland. Scientometrics, 52(1), 29-43.

Long, J. S. (1992). Measures of sex differences in scientific productivity. Social Forces, 71(1), 159-178.

Malouff, J., Schutte, N., \& Priest, J. (2010). Publication rates of Australian academic psychologists. Australian Psychologist, 45(2), 78-83.

Mauleón, E., \& Bordons, M. (2006). Productivity, impact and publication habits by gender in the area of materials science. Scientometrics, 66(1), 199-218.

Mauleón, E., Bordons, M., \& Oppenheim, C. (2008). The effect of gender on research staff success in life sciences in the Spanish National Research Council. Research Evaluation, 17(3), 213-225.

McDowell, J. M., Singell, L. D., \& Stater, M. (2005). Two to tango? Gender differences in the decisions to publish and coauthor. Economic Inquiry, 44(1), 153-168.

McDowell, J. M., \& Smith, J. K. (1992). The effect of gender-sorting on propensity of coauthor: implications for academic promotion. Economic Inquiry, 30(1), 68-82.

Mestre Escrivá, V., Martí Vilar, M., \& Samper García, P. (1996). Productividad científica en Psicología y la variable género. Un estudio a través de la Revista de Psicología General y Aplicada (RPGA). Revista de Historia de la Psicologi'a, 17(1-2), 121-133.

Moya-Anegón, F., Chinchilla-Rodríguez, Z., Vargas-Quesada, B., Corera-Álvarez, E., González-Molina, A., Muñoz-Fernández, F. J., et al. (2007). Scientific output by gender in Spain (Web of Science, 2004). In: 11th International Conference of the International Society for Scientometrics and Informetrics. 25-27 June, Madrid (Spain).

Instituto Nacional de Estad'istica, INEbase (2011). Retrieved Oct 2011. http://www.ine.es/inebmenu/ indice.htm

Nosek, B. A., Graham, J., Lindner, N. M., Kesebir, S., Hawkins, C. B., Hahn, C., et al. (2010). Cumulative and career-stage citation impact of social-personality psychology programs and their members. Personality and Social Psychology Bulletin, 36(10), 1283-1300.

Olivas-Avila, J. A., \& Musi-Lechuga, B. (2010). Análisis de la producción de los profesores funcionarios de psicología en España en artículos de revistas de la Web of Science. Psicothema, 22(4), 909-916.

Prpic, K. (2002). Gender and productivity differentials in science. Scientometrics, 55(1), $27-58$.

Puuska, H. M. (2010). Effects of scholar's gender and professional position on publishing productivity in different publication types. Analysis of a Finnish university. Scientometrics, 82(2), 419-437.

Renzulli, L. A., Aldrich, H., \& Moody, J. (2000). Family matters: gender, networks, and entrepreneurial outcomes. Social Forces, 79(2), 523-546.

Sax, L., Hagedorn, L., Arredondo, M., \& Dicrisi, F. A. (2002). Faculty research productivity: exploring the role of gender and family-related factors. Research in higher education, 43(4), 423-446.

Sonnert, G., \& Holton, G. (2006). Who succeeds in science? The gender dimension. New Brunswick: Rutgers University Press.

Stack, S. (2004). Gender, children and research productivity. Research in higher education, 45(8), 891-920.

Symonds, M., Gemmell, N., Braisher, T., Gorringe, K., \& Elgar, M. (2006). Gender differences in publication output: towards an unbiased metric of research performance. PLoS One, 1(1), e127.

Tower, G., Plummer, J., \& Ridgewell, B. (2007). A multidisciplinary study of gender-based research productivity in the world's best journals. Journal of Diversity Management, 2(4), 23-32.

Villarroya, A., Barrios, M., Borrego, A., Fr' 1as, A. (2008). PhD theses in Spain: a gender study covering the years 1990-2004. Scientometrics, 77(3), 469-483.

Ward, K. B., \& Grant, L. (1995). Gender and academic publishing. In A. E. Bayer \& J. C. Smart (Eds.), Higher education: handbook of theory and research (pp. 172-212). New York: Agathon Press Incorporated.

Webster, B. M. (2001). Polish women in science: a bibliometric analysis of Polish science and its publications, 1980-1999. Research Evaluation, 10(3), 185-194.

Xie, Y., \& Shauman, K. A. (1998). Sex differences in research productivity: new evidence about an old puzzle. American Sociological Review, 63(6), 847-870. 